\title{
Short report: Patterns of US federal autism research funding during 2017-2019
}

Lauren Harris ${ }^{1}$, Daniel Gilmore, BS, RDN, LD ${ }^{1}$, Anne Longo ${ }^{1}$, Brittany N. Hand, PhD, OTR/L ${ }^{1}$

${ }^{1}$ School of Health and Rehabilitation Sciences,

College of Medicine,

The Ohio State University

Corresponding authors:

Lauren Harris

The Ohio State University

453 West 10th Ave.

Columbus, OH 43210, USA

Email: harris.2633@buckeyemail.osu.edu

Brittany Hand

The Ohio State University

453 West 10th Ave.

Columbus, OH 43210, USA

Email: hand.58@osu.edu

This is a peer-reviewed, accepted manuscript. The final version will be published in the journal Autism and can be found here: https://doi.org/10.1177/13623613211003430 


\section{Scientific Abstract}

In 2017, the Interagency Autism Coordinating Committee (IACC), a federal advisory panel consisting of autism researchers and community members, recommended that funders of autism research prioritize research projects on: (1) treatments/interventions; (2) evidence-based services; and (3) lifespan issues. We sought to describe research funding since this recommendation was made. We searched the databases of the three largest federal funders of autism research in the United States (National Institutes of Health, Department of Education, and Centers for Disease Control and Prevention) for grants awarded during 2017-2019. We categorized grants as follows: autism screening and diagnosis, biology, risk factors, treatments and interventions, services, lifespan issues, or infrastructure and surveillance. We found that funding patterns remained largely consistent during 2017-2019. Biological research received a relative majority of funding (32.59\%), followed by treatments and interventions $(22.87 \%)$. While given higher funding priority by the IACC's recent budget recommendation, fewer funds were awarded to research areas like services (5.02\%) and lifespan issues (2.51\%), indicating a misalignment between funding patterns and the IACC budget recommendation. These findings emphasize the need for autism research funding to align with the IACC budget recommendations to best meet the needs of the autism community, particularly autistic younger, middle-aged, and older adults. 


\section{Lay Abstract}

In 2017, an advisory board consisting of autism researchers and community members recommended that funders of autism research prioritize research projects on: (1) treatments/interventions; (2) evidence-based services; and (3) lifespan issues. To describe funding in these areas since this recommendation was made, we searched the databases of the three largest federal funders of autism research in the United States. We found that the largest portion of federal funding during 2017-2019 was awarded to research on the biology of autism $(32.59 \%)$ and treatments and interventions for autism $(22.87 \%)$. Less funds were awarded to research areas that are high funding priorities by the IACC budget recommendation including services (5.02\%), and lifespan issues (2.51\%). Our findings emphasize that autism research funding is not consistent with the IACC budget recommendation to increase funding particularly to services and lifespan issues. We recommend that funding patterns should shift to better align with these priorities so that autism research may better serve the needs of the autism community. 


\section{Introduction}

Autism research funding in the United States (US) is largely informed by the Interagency Autism Coordinating Committee's (IACC) Strategic Plan. The IACC is an advisory committee, consisting of federal agencies and public stakeholders, that coordinates federal activities and advises the Secretary of Health and Human Services on topics related to autism (IACC, 2017). IACC public stakeholders include researchers, service providers, autistic individuals who advocate for themselves, and family members of autistic individuals, who each bring different perspectives and expertise to priority setting for autism research (IACC, 2017). Priority research areas identified by the IACC include autism screening and diagnosis, biology, risk factors, treatments and interventions, services, lifespan issues, and infrastructure and surveillance.

IACC's most recent budget recommendation (IACC, 2017) stated that areas in particular need of funding were: (1) treatments/interventions; (2) evidence-based services; and (3) lifespan issues. Historically, studies in these priority areas have received only modest amounts of funding. For example, in 2016, treatments and interventions received only $16 \%$ of autism research funding, services received $5 \%$ of funding, and lifespan issues received $2 \%$ of funding (Office of Autism Research Coordination,(OARC) et al., 2019), with similar patterns observed in 2014 (OARC et al., 2017). An Australian portfolio analysis of autism research funding found similar patterns concerning inadequate, or even no funding awarded to individual research areas, such as lifespan issues and infrastructure and surveillance (den Houting \& Pellicano, 2019). Funding in the United Kingdom is even more drastically skewed towards biological research (56\% of funding), with services and lifespan issues research receiving only $6 \%$ of autism research funding combined (Pellicano et al., 2013).

However, the extent to which recent US federal funding agencies have increased funding in these areas has not been studied. The purpose of this study, therefore, was to describe US federally funded autism research since this IACC recommendation was made. Understanding autism research federal funding patterns will help elucidate the extent to which 
the IACC's recommendation have been used to inform funding expenditures since its' publication.

\section{Methods}

\section{Search Strategy}

We searched the databases of the three largest US federal funders of autism research: National Institutes of Health (NIH), Department of Education (DoE), and Centers for Disease Control and Prevention (CDC) (IACC, 2016). We examined these funding agencies because they contain publicly available information about funded studies (including amount of funding awarded to each project), and they collectively award the majority (74\%) of all autism research funding in the US (IACC, 2016). Information about grants funded during 2017-2019 was obtained from NIH RePorter, the Institute of Education Sciences, and the US Department of Health and Human Services' Tracking Accountability in Government Grants System. Largely consistent with prior studies (den Houting \& Pellicano, 2019), our search terms were: "autism" OR "autistic" OR "Asperger" OR "AUTS1" OR "AUTS2." For the NIH, we searched for grants with a listed country of "United States and Territories," and an award type of "new." For the DoE, we searched the Institute for Education Sciences database entries listed as "grants;" database entries classified as "contracts" were excluded. Last, we searched the TAGGS database entries with a listed operating division of "CDC."

\section{Grant Selection}

Grants were eligible for inclusion in this analysis if they were newly funded during January $1^{\text {st }}, 2017-$ December $31^{\text {st }}, 2019$. Grants that were initially funded before 2017 and were renewed during 2017-2019 were not included because: (1) grants funded before 2017 were included in the IACC's prior Portfolio Analysis Reports on autism research spending; and (2) our objective was to understand the extent to which the most recent IACC Strategic Plan was used to inform funding expenditures since its publication. 
Next, the authors reviewed each grant to determine if the primary focus was autism. Two independent raters reviewed each grant's title, abstract, and scientific relevance (if available). The raters agreed on the inclusion or exclusion of $95 \%$ of the grants. In the event of a disagreement about whether or not a grant should be included (5\%), a third independent rater reviewed the study to determine inclusion or exclusion. Our search strategy identified 1,268 newly funded grants during 2017-2019. Of these, we identified 342 autism-focused grants.

\section{Grant Coding}

We coded grants according to the seven priority research areas identified by the 20162017 IACC Strategic Plan: (1) diagnosis and screening; (2) biology; (3) risk factors; (4) treatments and interventions; (5) services; (6) lifespan issues; and (7) infrastructure and surveillance (IACC, 2017). We categorized grants into these seven priority research areas (OARC et al., 2017, 2019), similar to previous studies (den Houting \& Pellicano, 2019; Pellicano et al., 2013). Each grant was coded by two blind raters. Our initial inter-rater agreement was $65 \%$. To resolve discrepancies, the team coded 20 grants together for calibration. Two raters then independently re-coded grants for which there was initially a lack of inter-rater agreement. After calibration, the inter-rater agreement was $91 \%$. For the grants where the raters disagreed on the category $(9 \%)$, a third, independent rater reviewed the grant and prior raters' codes to determine the category.

\section{Analysis}

We performed descriptive analyses of the amount of research funding allocated to each IACC Strategic Plan priority area. The current analyses were based on cash investments only; in-kind contributions to autism research were not included.

\section{Community Involvement}

While this study was informed by prior findings on priority research areas identified by IACC autism community, this study was not a community-based participatory research project. 


\section{Results}

Table 1 describes the number of grants, total funding, and grant size for each IACC Strategic Plan priority area. The 342 grants totaled just over $\$ 159$ million USD. Across the three years we examined, biological research received the largest amount of funding at $32.59 \%$ $(\$ 51,884,400.00)$, while lifespan issues received the smallest amount at $2.51 \%(\$ 3,992,400.00)$. The IACC priority areas of biology, treatments and interventions, and diagnosis and screening received the most funding during 2017-2019. Our analysis also revealed that while research in services received 5 more grants than infrastructure and surveillance, the total amount of funding awarded to services was less.

Table 1 also shows the allocation of research funding in each IACC Strategic Plan priority area over time. Biology- and risk factors-focused research, combined, received approximately 50\% of research funding in 2017 (55\%) and 2018 (43\%), and 37\% in 2019 . Treatments and interventions received approximately $20 \%$ of funds $(18 \%$ in $2017 ; 19 \%$ in 2019$)$, except in 2018 , when $33 \%$ of funding was awarded. The increased funding of treatments and interventions research in 2018 was due to five large grants, totaling over $\$ 8.5$ million collectively, awarded by the DoE. Research on services received small amounts of funding across all years examined (6\% in 2017; $8 \%$ in 2018; $1 \%$ in 2019). Lifespan issues received no funding in 2017 and only 4\% of research funding in 2018 and 2019.

\section{Discussion}

We analyzed autism research funding patterns during 2017-2019 from the three largest federal funders of autism research in the US to examine the extent to which funding patterns align with the IACC's budget recommendations. Our results were consistent with prior findings (OARC et al., 2017, 2019), indicating that biology-focused autism research received a relative majority of funding. Contributing to this pattern is the increase in biological research funding over other areas since 2008 (IACC, 2018). The IACC recommended an increase in funding to research on lifespan issues, services, and treatments and interventions. While treatments and 
interventions research received approximately $22.9 \%$ of autism research funding during the study period, funding awarded for lifespan issues and services research continues to be limited. We discuss our findings in these three priority areas below.

The IACC recommended increased funding for research on lifespan issues, and autistic individuals have also expressed a desire for increased research in this area (Frazier et al., 2018; Roche et al., 2021). However, research on lifespan issues only comprised $2.51 \%$ of the autism research funding during 2017-2019. This finding highlights the misalignment between recent autism research funding and the IACC's budget recommendations. As the number of autistic adults in the United States grows, there is an urgent need understand how to better meet this population's needs. For example, there is a particular need to develop models of healthcare delivery for autistic adults, as they are significantly more likely to be diagnosed with most physical and mental health conditions than the general population (Hand et al., 2020). Transition-age youth in particular face a gap in service availability as they approach adulthood (Turcotte et al., 2016), in part due to a scarcity of trained adult healthcare practitioners who are willing and able to meet their needs (Morris et al., 2019). While the IACC's strategic plan describes important lifespan issues work being done, such as employment programs for autistic individuals (IACC, 2018), further conversation is warranted to identify effective strategies to execute the IACC's recommendation to increase funding in this priority area.

Services research received only 5.02\% of autism research funding during 2017-2019. This priority area includes studies to improve cost-effective service delivery, service utilization and access, and practitioner training to better meet the needs of autistic individuals (IACC, 2017). In part, the amount of funding allocated to this priority area may be small because services studies may better fit within other priority areas. For example, research on healthcare services for autistic individuals as they age into and through adulthood would better fit under 
"lifespan issues." Additionally, some studies that aim to increase use of services, like vocational rehabilitation or occupational therapy, may better fit under "treatments and interventions."

In addition to lifespan issues and services, the IACC recommended an increase in funds allocated to treatments and interventions. Research on treatments and interventions received approximately $18-34 \%$ of total funding during $2017-2019$. Grants in this area were awarded $16 \%$ of total autism research funds in 2016 (OARC et al., 2019), and increased to $33 \%$ in 2018; however, 2019 marked a decline in the funding allocated to this area (19\% of autism research funds). This research category is critical for the development and testing of medications and interventions designed to help autistic individuals achieve their goals, which may ultimately lead to an improved quality of life and participation in valued activities. The variable amount of funding for this area in recent years may speak to a need for strategies to support sustained implementation of the IACC's budget recommendations.

\section{Limitations}

Although our inclusion/exclusion and categorization procedures were conducted with three reviewers, they carry with them the possibility of bias. It possible that some grants could have been categorized differently, which would impact our results. Our initial inter-rater agreement was lower than expected (65\%). Deciding whether to categorize grants as either risk factors or biology proved to be particularly challenging. Grants awarded to these areas often involved topics like biological and/or genetic mechanisms that made it hard to distinguish the focus of the grant. However, after we met as a group to re-calibrate our application of the categories, our inter-rater agreement rose to $91 \%$. This is a commonly used procedure in studies that involve multiple raters categorizing research studies into mutually exclusive categories (Polanin et al., 2019).

Since our data only includes newly funded grants while the IACC annual portfolio analysis includes both new and ongoing funding, our analysis may not be directly comparable to previous IACC analyses. Additionally, our search strategy did not identify all federally funded 
autism-focused grants in 2017-2019; while the IACC investigates 18 funders, we focused on the three largest federal funders of autism research in the US. Thus, we can be confident that the majority of federally funded autism research grants were included in our study.

\section{Conclusion}

Federal autism research funding patterns from 2017-2019 have remained relatively consistent across priority areas, with an emphasis on biological research. There continues to be a misalignment between the types of studies that receive federal funding and the research areas deemed most in most need of funding by the IACC. Increased funding should be directed towards research areas prioritized by the IACC's budget recommendation, including lifespan issues and development and delivery of evidence-based services, in order to advance research in these priority areas. 


\section{Works Cited}

den Houting, J., \& Pellicano, E. (2019). A Portfolio Analysis of Autism Research Funding in Australia, 2008-2017. Journal of Autism and Developmental Disorders, 49(11), 44004408. https://doi.org/10.1007/s10803-019-04155-1

Frazier, T. W., Dawson, G., Murray, D., Shih, A., Sachs, J. S., \& Geiger, A. (2018). Brief Report: A Survey of Autism Research Priorities Across a Diverse Community of Stakeholders. Journal of Autism \& Developmental Disorders, 48(11), 3965-3971. https://doi.org/10.1007/s10803-018-3642-6

Hand, B. N., Angell, A. M., Harris, L., \& Carpenter, L. A. (2020). Prevalence of physical and mental health conditions in Medicare-enrolled, autistic older adults. Autism, 24(3), 755764. https://doi.org/10.1177/1362361319890793

Interagency Autism Coordinating Committee (IACC). (2017). 2016-2017 Interagency Autism Coordinating Committee Strategic Plan For Autism Spectrum Disorder. https://iacc.hhs.gov/publications/strategic-plan/2017/strategic_plan_2017.pdf Interagency Autism Coordinating Committee (IACC). (2018). IACC Strategic Plan for Autism Spectrum Disorder 2018-2019. 77.

Morris, R., Greenblatt, A., \& Saini, M. (2019). Healthcare Providers' Experiences with Autism: A Scoping Review. Journal of Autism and Developmental Disorders, 49(6), 2374-2388. https://doi.org/10.1007/s10803-019-03912-6

Office of Autism Research Coordination, National Institute of Mental Health, \& on behalf of the Interagency Autism Coordinating Committee (IACC). (2017). 2014-2015 IACC Autism Spectrum Disorder Research Portfolio Analysis Report. https://iacc.hhs.gov/portfolioanalysis/2015/index.shtml

Office of Autism Research Coordination, National Institute of Mental Health, \& on behalf of the Interagency Autism Coordinating Committee (IACC). (2019). 2016 IACC Autism 
Spectrum Disorder Research Portfolio Analysis Report. https://iacc.hhs.gov/portfolioanalysis/2016/index.shtml

Pellicano, L., Dinsmore, A., \& Charman, T. (2013). A Future Made Together: Shaping autism research in the UK. 26.

Polanin, J. R., Pigott, T. D., Espelage, D. L., \& Grotpeter, J. K. (2019). Best practice guidelines for abstract screening large-evidence systematic reviews and meta-analyses. Research Synthesis Methods, 10(3), 330-342. https://doi.org/10.1002/jrsm.1354

Roche, L., Adams, D., \& Clark, M. (2021). Research priorities of the autism community: A systematic review of key stakeholder perspectives. Autism, 25(2), 336-348. https://doi.org/10.1177/1362361320967790

Turcotte, P., Mathew, M., Shea, L., Brusilovskiy, E., \& Nonnemacher, S. (2016). Service Needs Across the Lifespan for Individuals with Autism. Journal of Autism \& Developmental Disorders, 46(7), 2480-2489. https://doi.org/10.1007/s10803-016-2787-4 
Table 1: U.S. funding across IACC Strategic Plan categories during 2017-2019

\begin{tabular}{|c|c|c|c|c|c|c|c|c|c|c|c|c|}
\hline \multirow[b]{2}{*}{ IACC Area } & \multicolumn{3}{|c|}{2017} & \multicolumn{3}{|c|}{2018} & \multicolumn{3}{|c|}{2019} & \multicolumn{3}{|c|}{ Total } \\
\hline & $\mathbf{N}$ & $\begin{array}{c}\text { Total } \\
\begin{array}{c}\text { Expenditure* } \\
(\%)\end{array}\end{array}$ & $\begin{array}{l}\text { Median } \\
\text { Award } \\
(\mathrm{IQR})^{\star}\end{array}$ & $\mathbf{N}$ & $\begin{array}{c}\text { Total } \\
\begin{array}{c}\text { Expenditure } \\
(\%)\end{array}\end{array}$ & $\begin{array}{l}\text { Median } \\
\text { Award } \\
(I Q R)^{*}\end{array}$ & $\mathbf{N}$ & $\begin{array}{c}\text { Total } \\
\begin{array}{c}\text { Expenditure* } \\
(\%)\end{array}\end{array}$ & $\begin{array}{l}\text { Median } \\
\text { Award } \\
(\mathrm{IQR})^{*}\end{array}$ & $\mathbf{N}$ & $\begin{array}{c}\text { Total } \\
\begin{array}{c}\text { Expenditure* } \\
(\%)\end{array}\end{array}$ & $\begin{array}{c}\text { Median } \\
\text { Award (IQR)* }\end{array}$ \\
\hline Biology & 52 & 2182 (37.9) & $28(20,44)$ & 42 & 1505 (34.1) & $23(8,43)$ & 39 & $1501(26.1)$ & $33(9,53)$ & 133 & $5188(32.6)$ & $26(15,44)$ \\
\hline $\begin{array}{l}\text { Treatments, } \\
\text { Interventions }\end{array}$ & 24 & $1041(18.1)$ & $27(21,64)$ & 22 & $1492(33.8)$ & $44(18,88)$ & 15 & $1108(19.3)$ & $45(22,68)$ & 61 & $3642(22.9)$ & $38(21,68)$ \\
\hline Risk Factors & 27 & $1005(17.4)$ & $33(24,48)$ & 11 & $388(8.8)$ & $38(6,57)$ & 17 & $629(11.0)$ & $39(23,51)$ & 55 & $2022(12.7)$ & $34(21,50)$ \\
\hline $\begin{array}{l}\text { Diagnosis, } \\
\text { Screening }\end{array}$ & 10 & $522(9.1)$ & $21(14,68)$ & 15 & 405 (9.2) & $20(15,37)$ & 22 & $1233(21.5)$ & $50(24,77)$ & 47 & 2159 (13.6) & $25(16,73)$ \\
\hline Services & 10 & $371(6.4)$ & $25(20,40)$ & 9 & 357 (8.1) & $22(21,47)$ & 3 & $71(1.2)$ & $25(20,26)$ & 22 & $799(5.0)$ & $25(20,40)$ \\
\hline $\begin{array}{l}\text { Infrastructure, } \\
\text { Surveillance }\end{array}$ & 6 & $643(11.2)$ & $39(39,163)$ & 1 & $74(1.7)$ & $75(75,75)$ & 10 & $993(17.3)$ & $84(79,109)$ & 17 & $1711(10.8)$ & $84(78,114)$ \\
\hline $\begin{array}{l}\text { Lifespan } \\
\text { Issues }\end{array}$ & 0 & $0(0)$ & $\mathrm{n} / \mathrm{a}$ & 4 & $193(4.4)$ & $48(22,74)$ & 3 & $206(3.6)$ & $61(60,86)$ & 7 & $399(2.5)$ & $51(25,77)$ \\
\hline TOTAL & 129 & $5764(100)$ & $29(20,48)$ & 104 & $4414(100)$ & $25(15,51)$ & 109 & $5741(100)$ & $44(21,72)$ & 342 & $15920(100)$ & $33(20,60)$ \\
\hline
\end{tabular}

$\mathrm{N}=$ Number of Grants; IQR = Interquartile range

${ }^{*}$ Reported in tens of thousands of USD, rounded to the nearest whole dollar. 